\title{
Multi-Agent Parking Place Simulation
}

Citation for published version (APA):

Vrancken, T., Tenbrock, D., Reick, S., Bozhinovski, D., Weiss, G., \& Spanakis, G. (2017). Multi-Agent Parking Place Simulation. In Y. Demazeau, P. Davidsson, J. Bajo, \& Z. Vale (Eds.), Advances in Practical Applications of Cyber-Physical Multi-Agent Systems: The PAAMS Collection (pp. 272-283). Springer. Lecture Notes in Computer Science Vol. 10349 https://doi.org/10.1007/978-3-319-59930-4_22

Document status and date:

Published: 03/06/2017

DOI:

10.1007/978-3-319-59930-4_22

Document Version:

Publisher's PDF, also known as Version of record

Document license:
Taverne

\section{Please check the document version of this publication:}

- A submitted manuscript is the version of the article upon submission and before peer-review. There can be important differences between the submitted version and the official published version of record.

People interested in the research are advised to contact the author for the final version of the publication, or visit the DOI to the publisher's website.

- The final author version and the galley proof are versions of the publication after peer review.

- The final published version features the final layout of the paper including the volume, issue and page numbers.

Link to publication

\footnotetext{
General rights rights.

- You may freely distribute the URL identifying the publication in the public portal. please follow below link for the End User Agreement:

www.umlib.nl/taverne-license

Take down policy

If you believe that this document breaches copyright please contact us at:

repository@maastrichtuniversity.nl

providing details and we will investigate your claim.
}

Copyright and moral rights for the publications made accessible in the public portal are retained by the authors and/or other copyright owners and it is a condition of accessing publications that users recognise and abide by the legal requirements associated with these

- Users may download and print one copy of any publication from the public portal for the purpose of private study or research.

- You may not further distribute the material or use it for any profit-making activity or commercial gain

If the publication is distributed under the terms of Article $25 \mathrm{fa}$ of the Dutch Copyright Act, indicated by the "Taverne" license above, 


\title{
Multi-Agent Parking Place Simulation
}

\author{
Thomas Vrancken, Daniel Tenbrock, Sebastian Reick, Dejan Bozhinovski, \\ Gerhard Weiss, and Gerasimos Spanakis ${ }^{(凶)}$ \\ Department of Data Science and Knowledge Engineering, \\ Maastricht University, Maastricht, The Netherlands \\ $\{t$.vrancken, d.tenbrock, s.reick, \\ d.bozhinovski\}@student.maastrichtuniversity.nl, \\ \{gerhard.weiss, jerry.spanakis\}@maastrichtuniversity.nl
}

\begin{abstract}
Parking in large urban areas is becoming an issue of great concern with many implications (environmental, financial, societal, etc.). In our research we investigate automated dynamic pricing (ADP) as a mechanism for regulating parking place allocation. ADP means that the price for staying in a parking facility for a certain amount of time will fluctuate depending on the day and time of the week. In this paper, such a scenario is explored using multi-agent based simulation. Two kinds of agents are considered: drivers and parking facilities. Experiments are conducted in a real city environment in order to observe the impact of dynamic pricing, competition and demand increase. Results show that dynamic pricing application leads to better results (in terms of profit margin) for the parking facilities while it decreases drivers' utility.
\end{abstract}

\section{Introduction}

One of the arising problems of metropolitan areas is how to structure traffic flow and more specifically how to spread demand for parking so that is not concentrated in the city center, where most of the drivers want to go. A proposed solution would be the application of dynamic pricing, i.e. price fluctuation of parking depending on the day/time of the week. The desired outcome would be less traffic concentration in specific areas and homogeneous capacity filling at various car parks. Dynamic pricing has been already proposed in the parking space allocation domain $([2,5])$. Reaction of drivers to such techniques has also been studied $([4,6,8,9])$ but not in a thorough way and not using a multi-agent based model.

Goal of this paper is to build a multi-agent based simulation environment that will inspect the application of dynamic pricing and assess any changes in social welfare and parking agency profits. For this purpose, REPAST suite ${ }^{1}$ is utilized in order to implement two kinds of agents (drivers and parking facilities) and simulate the demand and supply of parking resources. Advantage of multi-agent

T. Vrancken, D. Tenbrock, S. Reick and D. Bozhinovski-Denotes equal contribution.

${ }^{1}$ https://repast.github.io/.

(C) Springer International Publishing AG 2017

Y. Demazeau et al. (Eds.): PAAMS 2017, LNAI 10349, pp. 272-283, 2017.

DOI: 10.1007/978-3-319-59930-4_22 
approach is that we are able to model interactions between the different parties in an intuitive way. Without loss of generality, the studied context was the city of Maastricht, Netherlands and the simulation was examined from the perspective of the parking agency that owns most of current parking facilities in the city, namely Q-Park. This offered the opportunity to assess the effect of dynamic versus static pricing and then inspect the effect of competition and of a drastic demand increase. Results of different simulations confirm that applying dynamic prices increases consequently the profits of the car parking facility, though it does not improve social welfare. Increasing competition however does increase social welfare while decreasing Q-Parks profits. Finally, increasing demand will drastically increase profits while decreasing social welfare.

The remainder of the paper is organized as follows. Section 2 will present the context of the simulation while Sect. 3 will then present the multi-agent model part. Experiments and results are presented in Sect. 4 while lastly, Sect. 5 concludes the paper.

\section{Context and Data Generation}

The simulated environment represents the city center of Maastricht, Netherlands. The simulation is run on a grid which is laid upon the city map. Each grid field is approximately $22 \mathrm{~m} \mathrm{x} 22 \mathrm{~m}$ wide and the simulated environment holds $120 \times 80$ of those grid fields. While in real life, drivers will only use those grid fields which match with streets, this restriction was ignored for the simulation in order to keep the multi-agent approach to dynamic pricing in a topic related context. Therefore a street simulation was not planned for the purpose of this paper. There are in total 13 car parks in Maastricht (owned by Q-Park) and they are included as parking facilities on the map and positioned at respective grid fields which correspond to their actual position.

Both capacity and pricing of the real parks are used as initial variables for the car park agents and also as a comparison between static and dynamic pricing. They are presented in Table 1 (Fig. 1).

While data for parking agencies could be retrieved, this was not the case for driver data (i.e. number of drivers, desired destination, price ideas, planned duration of stay, preferred walking distance). In order to still run the simulation on a close-to-realistic set of drivers, the dataset for the drivers was generated by gathering ideas about realistic values and adding a randomization. In order to make the driver data easily extendable for additional parameters, the following CSV (comma separated values) format was used:

$I D$, start.X, start. $Y$, destination.X, destination. $Y$, arrival, max. price per hour, duration of stay, max. walking distance, initial time, day

Each driver has an ID which is unique for the day it spawns on the map. The starting point of the driver is random (denoted by start.X and start.Y), while the destination of the driver is normally distributed around the center of the map (destination.X and destination.Y). The distribution is ellipsoidal with a maximum of $1 / 3$ of the grids width in direction of $x$ and a maximum of $1 / 3$ of the grids heights in direction of $y$. 
Table 1. Q-Park facilities of Maastricht

\begin{tabular}{l|c|l|l}
\hline Name & Capacity & Price per hour & Max. price per day \\
\hline Cabergerweg & 698 & $1.43 €$ & $9.00 €$ \\
\hline Sphinx-terrein & 500 & $2.22 €$ & $13.00 €$ \\
\hline De griend & 351 & $2.22 €$ & $13.00 €$ \\
\hline Bassin & 407 & $2.73 €$ & $25.00 €$ \\
\hline P + R station Maastricht & 335 & $1.89 €$ & $13.00 €$ \\
\hline Mosae forum & 1082 & $2.73 €$ & $25.00 €$ \\
\hline Vrijthof & 545 & $3.53 €$ & $35.00 €$ \\
\hline P + R meerssenerweg & 65 & $1.89 €$ & $13.00 €$ \\
\hline O.L. vrouweparking & 350 & $2.73 €$ & $25.00 €$ \\
\hline Plein 1992 & 449 & $2.22 €$ & $13.00 €$ \\
\hline De colonel & 297 & $2.22 €$ & $13.00 €$ \\
\hline Bonnefantenmuseum & 303 & $1.43 €$ & $25.00 €$ \\
\hline Brusselse poort & 610 & $1.43 €$ & $25.00 €$ \\
\hline
\end{tabular}

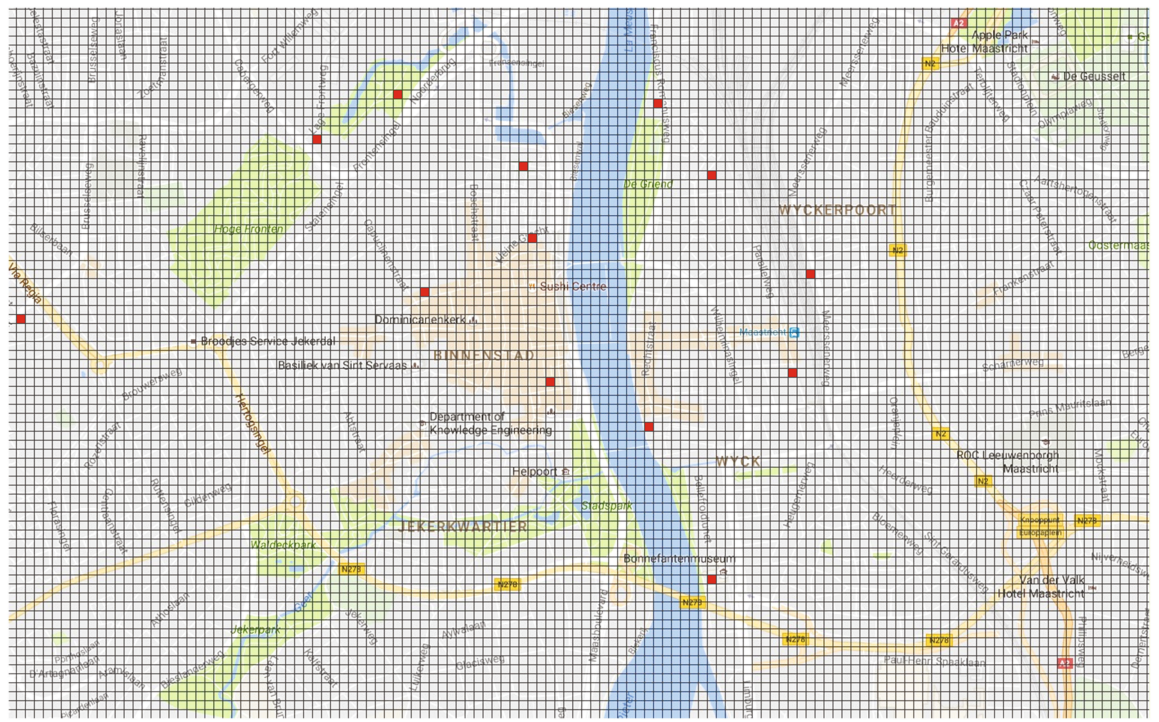

Fig. 1. Spreading of car parks (red squares). (Color figure online)

For a timestamp $T$ a (random) number of driver $N_{T}$ spawns at $\mathrm{T}$ minus $90 \mathrm{~min}$ in order to give the drivers enough time to reach their destination (i.e. time $T$ is the desired time for the drivers to arrive at their destinations). Duration of stay for these drivers is also random. Timestamps are measured in minutes and represent the clock time for a specific day. The desired arrival time of the 


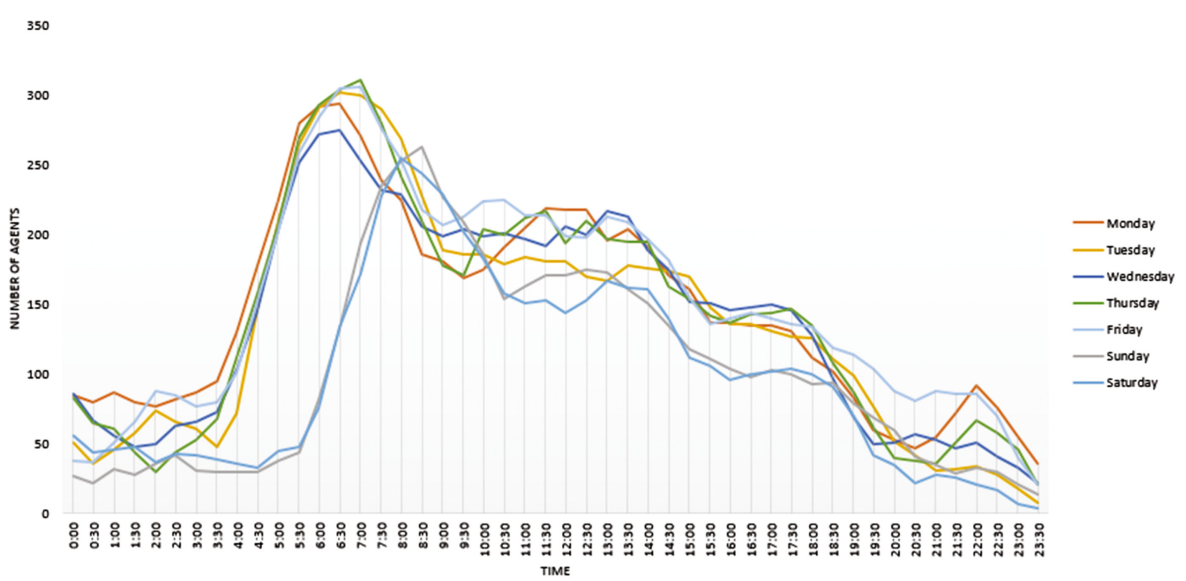

Fig. 2. Number of driver agents per day of the week

drivers is spread $+/-15$ minutes around $T$. Every driver will try to reach their destination on time, while choosing their parking location according to their preferred maximal price per hour and maximal walking distance. These two variables are influenced by a random factor as well, resulting the maximal price per hour to span from $0.80 €$ to $1.20 €$ and the walking distance from 800 to $1200 \mathrm{~m}$ for every driver.

Note that the arrival time and duration of stay of the drivers are randomized to reflect reality. That is, during the week, more drivers spawn in the morning to represent workers wanting to arrive to their workplace. Those have a duration of stay randomized between 7.5 and 8.5 hours, which should fit the average worker's schedule. During weekends, drivers are expected to show up later. They will also be more spread over the day, which means that more drivers will enter the system during the afternoon. The peak that was previously at 7:00 is postponed to around 9:00. Overall, there are less drivers than for the workdays. The driver data for weekdays can be seen in Fig. 2 .

\section{Model Implementation}

The simulation uses two kinds of agents: drivers and parking facilities. Drivers can have two kinds of behavior: guided or explorer. This section will present how those agents behave and what assumptions were used to model them.

\subsection{Driver Agents}

Drivers can behave in two possible ways. They can either be guided drivers or explorer drivers. Guided drivers are assumed to behave rationally and to have total knowledge about prices and locations of all of the parking facilities in the environment. Thus, the first thing such a driver does when appearing in 
the simulation system is to select the parking that maximises their "utility". The concept of utility is widely used in Economy and Game Theory and is a representation of the happiness of an agent (or consumer, here both) as a function of several parameters (here mainly price of the parking and distance from the parking to their destination) [7]. The model for drivers' utility function used in this simulation is presented at the end of this subsection.

Once the driver decided which parking would maximise their utility, they move to it and try to park. If the parking is at maximum capacity, the driver will select the parking that provides him with the maximum utility in the remaining parking available and repeat the process. It is possible that all of the possible parking options for a driver would create a negative utility. In such a case, the driver agent exits the system and is assumed to find another mean to arrive to their destination. Intuition behind the guided drivers is that as they know the prices of all of the parking agencies, they make a rational decision on which one to choose and they will react to change in prices rather fast.

On the other hand, explorer drivers behave more like real life parking consumers, having less knowledge about what parking options are available to them. Their difference from guided drivers is that they are driving around until they find a parking spot (i.e. they drive to the parking place closest to them) and check if there is a place left and if the price and location of the parking creates a utility for them. If not, then they find another parking and the process is repeated. Intuition behind explorer drivers is that they will slow down the reaction in demand for a parking if the prices increase. Note that the utility is calculated using the same utility function as for the guided drivers (see below), though in the case of explorer drivers it is calculated only to check whether it is worth it for the explorer to use the parking facility just found.

As stated earlier, each driver must be able to derive how happy they would be from parking in a certain facility, i.e. the utility from that outcome. The utility function of a certain driver $i$ to park in a certain parking facility $j$ is defined using the following Equations.

$$
\begin{gathered}
u_{i, j}=C_{i}-p r_{i} \cdot\left(P_{i, j}\right)^{u}-w_{i} \cdot\left(W_{i, j}\right)^{v} \\
P_{i, j}=\alpha \cdot \text { price }_{j} \cdot \text { duration_of_stay } \\
W_{i, j}=\beta . \text { distance_to_destination }_{i, j}
\end{gathered}
$$

In this model, $C_{i}$ is the constant representing the utility the driver would receive by arriving to their destination, without having to walk or to pay for a parking place. It is a random value attributed to each driver agent. $P_{i, j}$ is a value representing how much driver $i$ will have to pay to park for their entire duration in parking $j$, scaled by the constant $\alpha$. Similarly, $W_{i, j}$ represents the effort from driver $d_{i}$ to walk from the parking $p_{j}$ to his destination, scaled by $\beta$. The constants' $\alpha$ and $\beta$ are used to enable a fair comparison of the impact of meters and euros on the utility.

The coefficients $p r_{i}$ and $w_{i}$ represent the emphasis of agent $i$ on paying a certain amount of money and walking a certain distance respectively. 
Indeed, every agent is not assumed to have the same change in utility from walking a certain distance or paying a certain price. That is, another agent, say $k$ might be willing to have a lower utility function for the same price. Agent $k$ will then have a higher price emphasis $p r_{k}$, that is $p r_{k}>p r_{i}$. The walking emphasis $w_{i}$ is used in the same way. Both are randomly assigned to each driver and range between 1 and 1.5. It represents the agent personality and this heterogeneity in driver agent's personalities improves the realistic depiction of the simulation. Note that the distribution of coefficients $p r_{i}$ and $w_{i}$ can be changed to reflect a different environment (e.g. another city).

The powers $u$ and $v$ are both set to 0.9 . They create non-linearity in the impact of price and effort on the walking distance. Indeed, it is fair to assume that a fixed increase in price (e.g. a $1 €$ increase) would have more impact on a customer whose original price to pay was low (e.g. original price of $2 €$ ) than on a customer whose original price to pay was higher (e.g. original price of $200 €)$. The concavity of the utility function, ensured by setting $u \in(0,1)$ and $v \in(0,1)$, will reflect this concept in the driver's decision process.

\subsection{Parking Agents}

Parking agents were used to represent two different kinds of parking facilities. The parking agents can either be operated by the sole owner of parking facilities (in the case of Maastricht that is Q-Park) and their goal is to adapt their prices in order to optimize their profit, or they can be a competitor which just uses a static pricing model (in the case of Maastricht that can be the parking at municipality's public places). A parking facility in the real world can be described by location, name, price, capacity and operator. Name, location, capacity and operator are assigned to the agent during initialisation and are fixed.

Every parking agent can apply seven pricing schemes. Each scheme is mapped to one specific day of the week and is fully independent from the other pricing schemes. Parking facilities can react to the driver agents, but do not interact with them (i.e. there is no negotiation). The parking facilities possess an internal clock used for keeping check of the parked drivers and to decide which pricing scheme to apply. Once a driver checks in at a car park, the id of the driver and their duration of stay are saved in a list. Similarly, car park agents check whether drivers have to be checked out using that list. If the parking facility is applying dynamic pricing, then at the end of every week they will update their pricing model in order to improve their profit. This process is described in the following Subsection.

\subsection{Pricing Scheme}

The final price paid by the driver will be computed based on three parameters: the price per minute (most important), a minimal price every customer has to pay for the stay and a maximum price one would have to pay (i.e. staying a full day might have a fixed price lower than the hourly computed price of staying that amount of time). On top of that, there is a in- and deflation parameter 
defining the price per minute. The default value for this factor is 1 and the intuition is that if the value becomes lower or higher than 1 during optimisation, this will result in the price changing with every successive hour stayed in the parking facility. For example, if the price per hour is 1 euro and the inflation value is 1.10 then the driver will pay, according to what can be seen in Table 2 .

Table 2. Price adjustment with inflation

\begin{tabular}{l|l|l}
\hline Hour & Price for that hour & Full price \\
\hline 1 & 1 & 1 \\
\hline 2 & 1.1 & 2.1 \\
\hline 3 & 1.21 & 3.31 \\
\hline 4 & 1.331 & 4.641 \\
\hline
\end{tabular}

The final price can also be scaled depending on the current capacity of the parking. The normal price will be payed if the capacity of the car park is between $30 \%$ and $70 \%$. If the capacity moves out of these boundaries the price will be linearly adjusted to increase the price according to the parameter. For instance, At $0 \%$ or a $100 \%$ the price will change by the percentile amount of the parameter.

The parameters are updated using gradient decent. To do this, the parking agent decides to update one parameter each week. The update method is given the percentile change in revenue. The standard equation for an update, if the last update increased the size, can be seen in Eq. 4. If the price was decreased in the last update, Eq. 5 is used. In these Equations, $\delta$ denotes the learning rate and $\gamma$ denotes the percentile change in revenue in comparison to last week.

$$
\begin{aligned}
& x_{i+1}=x_{i}+\delta \cdot x_{i} \cdot(\gamma-1) \\
& x_{i+1}=x_{i}-\delta \cdot x_{i} \cdot(\gamma-1)
\end{aligned}
$$

Every parameter is updated five times in a row before the next parameter will be updated. The default value for the $\delta$ is empirically set to 0.3 . If $\delta$ is assigned a value too high, it can lead to rapid price changes and the algorithm will fail to converge. Setting the $\delta$ too low will increase the convergence time. Parameters are not allowed to fall below 0 (such updates are not possible). For improved convergence speed and more robust gradient decent (e.g. against ill chosen learning rates), Adaptive Moment Estimation (ADAM) [3] is implemented within REPAST. ADAM is a method to compute adaptive learning rates for parameters by storing a exponentially decaying average of past squared gradients.

\section{Simulation Results}

This Section will present three experiments that were conducted with the developed simulation. Performance measures will be profits for the parking owner(s), social welfare and average price. 
Profits of the owner of certain parking facilities are the sum of the profits for all of those parking facilities. Note that for experiments 1 and 3 there is a unique parking owner (namely Q-Park). Profits are defined as the revenues minus the costs [7]. Without loss of generality we considered a fixed value for costs, so revenues and profits are directly analogous.

Social welfare is calculated as the sum of the utilities of all of the drivers in the system. It is the synonym of consumer welfare (which is actually shown to fluctuate in the economic way it theoretically should). The program is set to add a utility of -10000 to the social welfare for each of the drivers that do not manage to find a parking providing them with a positive utility, hence that exit the system. This high value represents that one has a greater loss in utility by not finding a parking at all than by finding one that is just relatively too expensive.

\subsection{Experiment 1: Dynamic Pricing vs. Static Pricing}

The first experiment conducted is meant to study the impact of dynamic pricing on the profits of the sole car park owner (Q-Park) and the social welfare. For this purpose, two simulations were run, one using the original static prices and one using dynamic pricing. The simulation ran for 34 (simulated) weeks in total. For the static pricing run, all car parks agents solely used the static prices presented in Table 1. In comparison to this, the same time span was covered in a second run, but with all car park agents defined to update their pricing according to the dynamic pricing approach. Price adjustment happens on a weekly basis, as explained in Sect.3. For both runs, the same set of drivers with the same predefined preferences and destinations was used in order to compare just the performance of static pricing against dynamic pricing. The amount of drivers as well as their desired duration of stay corresponds to the graphs and tables from Sect. 2.

The results of these simulations are presented in Figs. 3 and 4. The first conclusion is that dynamic pricing increases the profits for Q-Park. Figure 3 shows that, after 35 weeks of adaptation, the profits using ADP are about $23000 €$ higher than the ones using static pricing. This represents a $32 \%$ increase in profit which shows that it is really profitable for car park agencies to apply dynamic pricing. The fluctuations in profits under dynamic pricing are due to the time that parking agents need to adapt the prices to demand. This effect decreases in the long run (prices fluctuate less in the long run, considering stable demand).

Yet, social welfare turned out to be always slightly lower using dynamic pricing. Note however that this model of social welfare does not include utility for regulating traffic flow, avoiding traffic jams, etc. For example, it is expected that dynamic pricing will spread demand for parking across the town, hence making the traffic flow more homogeneous. It is fair to assume that this effect should increase social welfare. Furthermore, there is no utility penalty for arriving to a parking facility that attained its maximum capacity and having to drive to another facility. Such a situation occurs way less often under dynamic pricing. 


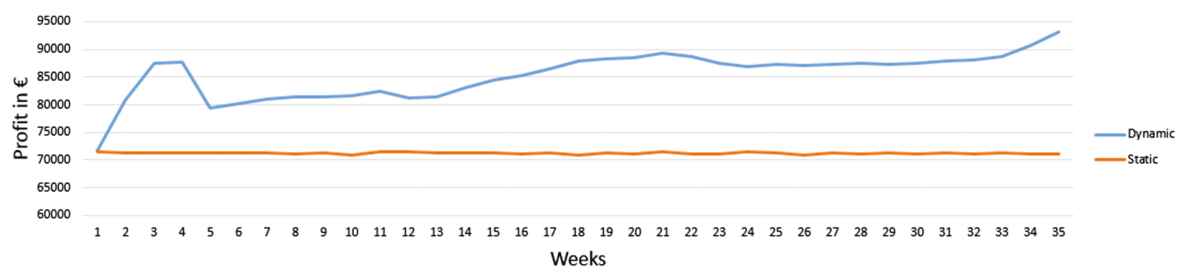

Fig. 3. Profits with dynamic vs static pricing scheme

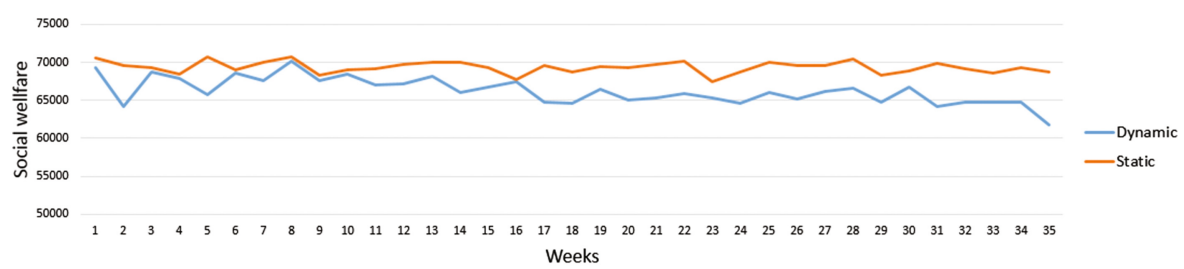

Fig. 4. Social welfare with dynamic vs static pricing scheme

\subsection{Experiment 2: Competition vs. Monopoly}

The second experiment will measure the impact of increased competition. That is, we relax the assumption that all car parks belong to the same owner and instead, there are some competitors which try to maximize their summed profits. In this case, we assumed that 5 of the main parking facilities belong to a competitor. Those 5 parking facilities were selected to be located near the center, hence bringing them leverage to attract drivers. These five car parks will use static pricing, while the rest of the car parks will use dynamic prices and aim at maximising their accumulated profits (obviously without considering the profits of the static car parks).

Figure 5 shows the average price per week of the 8 car parks that always apply dynamic pricing, under the scenario that the other do as well and under the scenario that they do not. One can observe that those 8 car parks have to set their prices much lower when there is competition. The insight is straightforward: Under monopoly, they can coordinate their prices and set them high, while under competition they have to follow the lowest prices in order to still attract customers.

On the other hand, Fig. 6 shows that social welfare drastically increases with competition. This follows the fact that the "outer-city" car park facilities that are assumed to still belong to one owner had to decrease their price in order to steal customers from the competition. This accords with a fundamental principle of free trade economy. Increasing competition will force the suppliers to bring down their price, hence increasing consumers welfare. That is why free trade and competitive markets are enforced in many economies. As a matter of fact, the European Commission already fined some companies that undertook some actions to settle them as monopolies [1]. 


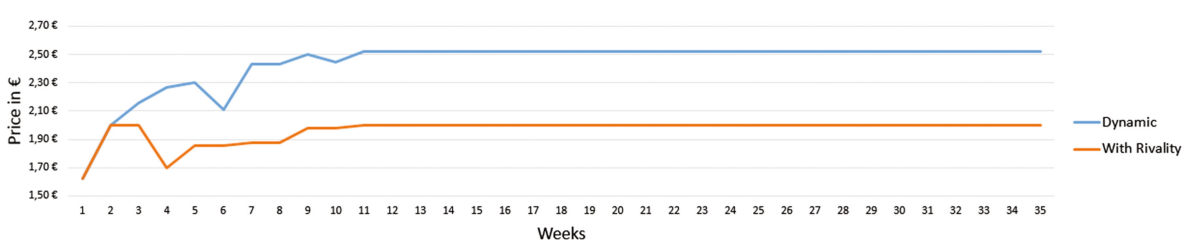

Fig. 5. Prices with competition vs monopoly

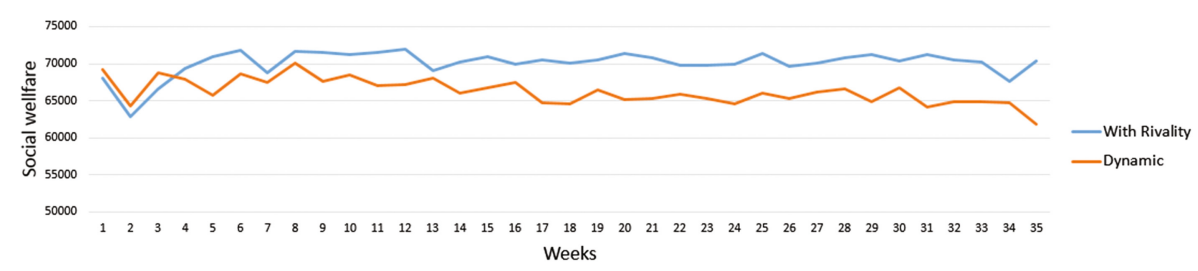

Fig. 6. Social welfare with competition vs monopoly

\subsection{Experiment 3: High Amount vs. Normal Amount of Drivers}

The last experiment tested the dynamic and static run from the first scenario on a bigger driver dataset. For this purpose, the amount of drivers from experiment 1 was increased to approximately 3 times as much as before. The situation for the car parks does not differ from experiment 1 . The insight behind this test is to observe the consequences of a drastic increase in demand.

Figure 7 shows the profits of static and dynamic pricing under the assumption of higher demand ("many drivers" line) and normal demand ("normal drivers" line, referring to normal number of drivers). One can observe a drastic increase in the profits of the sole car park owner with higher demand and this is not surprising since higher demand means higher profits. The difference in profit is also higher in the case of dynamic pricing. Furthermore, it is more valuable to be able to spread demand over the different parking facilities when there is a high demand. Indeed, one of the positive aspect of dynamic pricing is that the parking owner can distribute better the demand. That is, ensuring to minimise the number of parking facilities that become full by spreading demand over the different parking facilities by increasing the prices where there is a high demand or decreasing the prices where there is a low demand. That aspect is of course more valuable when there are much more drivers, as a full parking situation is more likely to happen.

Figure 8 shows the change in the social welfare following this experiment. Recall that when a driver finds no available spot that yields a positive utility, then they exit the system and adds a -10000 utility to the social welfare. With three times more drivers, we have two consequences: Firstly, the prices of parking facilities increase and secondly, parking facilities will become full much faster, especially where there is high demand. This forces some drivers to consider parking facilities further away from the city center (i.e. their destination). 
Those parking facilities will also have higher prices. These effects combined (higher prices and fewer options) drastically increase the number of drivers that cannot find a parking facility that suits their bound on utility. Hence, it drastically brings down the social welfare.

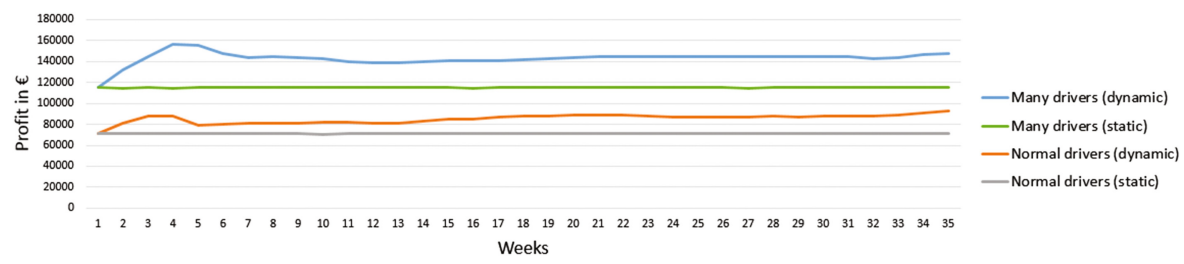

Fig. 7. Profits with competition vs monopoly

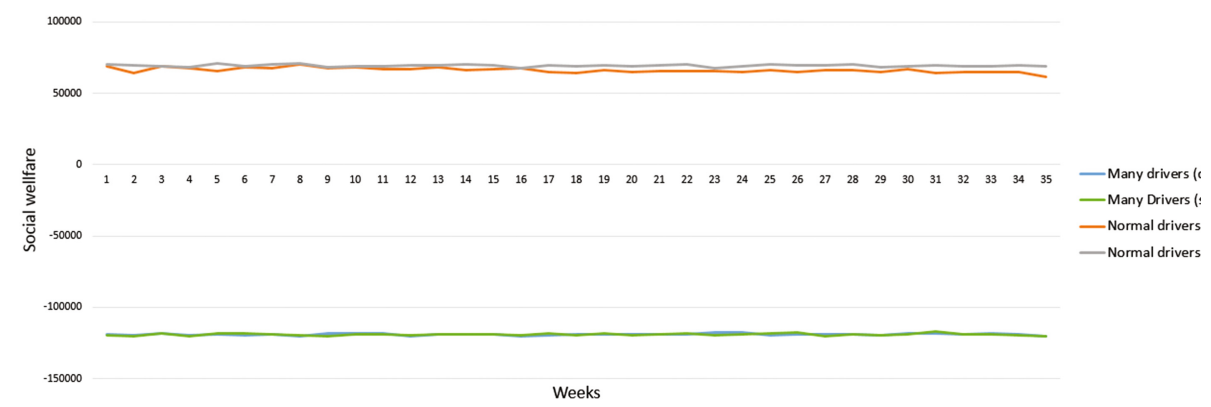

Fig. 8. Social welfare with competition vs monopoly

\section{Conclusion}

In this paper, a simulation environment to assess effectiveness of dynamic pricing to parking space allocation was presented. By carefully implementing the agents' behavior (drivers and car parks), it was shown that a multi-agent simulation is possible to be used to examine market's reaction to different effects. The conducted experiments lead to some interesting conclusions. First of all, using dynamic pricing can be very profitable for a car park agency. Moreover, dynamic pricing has a larger impact on profits when the supplier is in a monopoly situation and/or when there is high demand. The results are interesting in as far as they indicate that, because of the possibly negative implications of automated dynamic pricing on the benefits for the car drivers (i.e. social welfare), ADP calls for regulatory measures, which are to be specified in negotiation with the private parking agencies by the city authorities or even are to be regulated by law at a national level. Such regulations may take into account factors such as environmental pollution, traffic flow/jams, etc. in order to counter-balance 
purely economic factors. Experiments are also in accordance with the related economic principles. Note as well that such simulation could be used to assess the potential of applying dynamic pricing to a whole range of other services.

In this paper, real data for costs of each car park or for the drivers were not available in order to bring simulation closer to reality. Having such information would severely improve the validity of the results. Another improvement would be to assess the effect of simulation (which in any case is generically designed) on an environment with more competitors and also higher amount of drivers that exceed the total limit of parking slots. This could lead to some potentially interesting results of how market will react.

Finally, the behaviour of agents (both car park and driver agents) can be further improved by extending the artificial data or using real data from actual traffic. This especially refers to the assumption that drivers can drive on every grid field. By limiting the movement to grids that represent actual streets, the simulation could also be used to simulate traffic and maybe even used to spread the traffic flow across the city by making use of the dynamic pricing for the different car park. This is a promising future research direction with much greater impact on many interested stakeholders (city, drivers, car parks).

\section{References}

1. European Commission Press Release: Competition activity run high in (2000). http://europa.eu/rapid/press-release_IP-01-698_en.htm?locale=en. Accessed 06 Feb 2017

2. Amir, K., Yao-Chun, S., Xu, Z., Yi, H.: iParker-a new smart car-parking system based on dynamic resource allocation and pricing. IEEE Trans. Intell. Transp. Syst. $\mathbf{1 7}(9), 2637-2647$ (2016)

3. Kingma, D.P., Ba, J.: ADAM: a method for stochastic optimization. In: International Conference on Learning Representations. arXiv preprint arXiv:1412.6980 (2015)

4. Mackowski, D., Bai, Y., Ouyang, Y.: Parking space management via dynamic performance-based pricing. Transp. Res. Procedia 7, 170-191 (2015)

5. Meier, R.: Mechanisms for Stability and Welfare: Increasing Cooperation Among Self-Interested Agents. AI Access (2014). ISBN:978-1-291-97962-6

6. Silva, M., Martín, G.: Agent-based parking occupancy simulation (2015)

7. Perloff, J.M.: Microeconomics New Myeconlab Access Card: Theory and Applications with Calculus. Prentice Hall, Upper Saddle River (2011)

8. Steenberghen, T., Dieussaert, K., Maerivoet, S., Spitaels, K.: SUSTAPARK: an agentbased model for simulating parking search. URISA J. 24(1), 63-77 (2012)

9. $\mathrm{Xu}, \mathrm{H}$., Zhou, J., Xu, W.: A decision-making rule for modeling travelers' route choice behavior based on cumulative prospect theory. Transp. Res. Part C: Emerg. Technol. 19(2), 218-228 (2011) 